\title{
Creación literaria e imaginario colectivo: discusión sobre el concepto de utopía en la realidad latinoamericana
}

\author{
Leonardo Merino Trejos \\ Programa Estado de la Nación \\ Costa Rica
}

\begin{abstract}
Resumen
Este artículo pretende discutir el concepto de utopía que se ata a las formas literarias, para proponer uno que le reivindique -a la luz de la realidad latinoamericana- como un espíritu del imaginario colectivo, que podemos ver expresado en la literatura, tanto como en toda creación y expresión humana. Se intenta revisar el concepto con reglas rígidas del género literario, confrontado a su expresión en América Latina, donde la utopía superó la idea de sitio, de género y de modelo organizativo regulador, mostrándose más bien como una actitud del pensamiento y como un espíritu constante en el imaginario colectivo. Se revisan algunos conceptos claves de utopía, tratando de desvincularla del texto en sí, para ligarla al imaginario que este refleja.
\end{abstract}

Palabras claves: utopía, literatura latinoamericana, sociedad latinoamericana, contexto histórico

\begin{abstract}
This article discuss the concept of utopia concerning literary forms, in order to propose one who recovers this concept as a spirit from collective "imaginario", expressed through literature as a human creation and expression. We also intend to review this concept based up to its expression in Latin America, where utopia is over the idea of site, gender, and regulator organizing model instead of an attitude of thought and a constant spirit in collective "imaginario". Some concepts of utopia are reviewed to separate this one from the text itself and to tie it to its own "imaginario".
\end{abstract}

Key words: utopia, Latin American literature, Latin American society, historical context 


\section{Presentación}

$\mathbf{N}$ os dice Alfonso Reyes que "desde que el hombre ha dejado constancia de sus sueños, aparece en forma de raro presentimiento la probabilidad de un mundo nuevo" (en Durán, p.11). Por eso, hablar de utopía es hablar de los sueños humanos. Aunque hoy esa palabra ilustra casi toda idealización, su espíritu se plasmó a lo largo de los siglos como la esperanza en una mejor forma de organización de la convivencia humana, sustentada en elementos constantes en el plano de los ideales, pero difícilmente concretados en la historia.

Nacida como forma literaria, hoy vemos la utopía en casi todos los aspectos de la vida. Se habla cotidianamente de la utopía como cualquier aspiración, difícil de alcanzar, que se refiera al plano personal, a los proyectos familiares, a determinados objetivos gremiales, a expectativas tecnológicas o aspiraciones ideológicas concretas.

Paralelamente, se habla de utopía en el plano escrito de la construcción narrativa de sociedades imaginarias ideales, en las cuales se establecen reglas y se proyectan posibles desarrollos futuros de la realidad. Es decir, se ve la utopía como el momento en que, directa o intencionalmente, un autor elabora, en el marco de la ficción, una propuesta de organización social proyectada generalmente a futuro.

Por lo tanto, aunque la utopía pueda considerarse un género literario, también es un concepto que se ha cargado de sentido en sí mismo. Es decir, evolucionó como un espiritu o actitud de pensamiento que se relaciona con nuestros ideales, anhelos o incluso temores.

La historia de América Latina y sus procesos de dominación-liberación e hibridaciones cultural, social, económica y política, muestra formas creativas, distintas e incluso a veces implícitas de construir sus propias utopías. En la convivencia de lo artístico y lo histórico, el pensamiento utópico latinoamericano será fácil de encontrarla en un relato indígena colonial, en escritos de Simón Bolívar, en poesías de José Martí, en novelas de García Márquez, en canciones de Atahualpa Yupanqui o en escritos del Subcomandante Marcos. Y así también en todo el imaginario colectivo.

Por eso, este artículo pretende discutir muy preliminarmente el concepto de utopía que se ata a las formas literarias, para proponer uno que le reivindique -a la luz de la realidad latinoamericana- como un espiritu del imaginario colectivo, que podemos ver expresado en las obras literarias, tanto como en toda forma de creación y expresión humanas. Intentaremos demostrar que no son las reglas rígidas de un género literario las que pueden hacer utópica nuestra literatura, sino la presencia de la utopía que Latinoamérica refleja en su creación, porque es parte de su historia.

\section{Realidad latinoamericana y creación literaria: sobre el concepto utopía y nuestro imaginario colectivo}

El concepto de utopía tiene implicaciones cotidianas, científicas, artísticas, políticas e ideológicas que, durante cinco siglos de permanencia, han conllevado muchas definiciones y sentidos. Sin embargo, eso 
hace más difícil buscar un concepto propio, pues la idea de utopía ha rebalsado cualquier delimitación.

La palabra utopía es acuñada en 1516 en la obra de Tomás Moro, y significa "lugar que no existe", situado en "ninguna parte". Su libro inaugura el uso del término y toda una tradición literaria. Ya en 1529 apareció la palabra utópico y su conversión en adjetivo fue cambiando su carácter hacia "un estado del espíritu, sinónimo de actitud mental rebelde, de oposición o de resistencia al orden existente por la proposición de un orden radicalmente diferente" (Ainsa, 1990, p.57).

Comencemos por la definición de la utopía en cuanto género literario, según el modelo de Moro. Trousson la ubica cuando...

...en el marco de un relato (lo que excluye los tratados políticos), figure descrita una comunidad (lo que excluye la robinsonada), organizada según ciertos principios políticos, económicos, morales, que restituyan la complejidad de la vida social (lo que excluye la edad de oro y la arcadia) ya se presente como ideal a realizar (utopía constructiva) o como previsión de un infierno (la antiutopía moderna) y se sitúe en un espacio real o imaginario o también en el tiempo o aparezca, por último, descrita al final de un viaje imaginario, verosímil o no. (Trousson, 1995, p.54)

Esta definición se adecua al género literario del modelo de Moro, pero no a lo que el concepto ha calado en el imaginario colectivo. La visión de la utopía como espíritu de ese imaginario es la que se construye en el pensamiento latinoamericano, lo que se ve en los muchos estudios sobre su presencia, pese a no haberse producido más que unas pocas obras en el modelo definido por Trousson.

Este autor también hace una salvedad cuestionable al afirmar que "la descripción de la utopía como género permite escapar a su confiscación por las ideologías" (Trousson, 1995, p.28). Asegura que sea cual sea su carácter ideológico, la utopía "funciona" de la misma manera. Sin embargo, si la utopía tiene una intención crítica y transformadora, no seguirá la misma lógica sirviendo para ideologías distintas. Esto lo refuerza Hinkelammert (1995), cuando afirma que hay dos visiones utópicas: aquella que es instrumento del poder y niega sus alternativas; y las utopías en cautiverio, que son las visiones críticas de la realidad y la esperanza en mundos mejores, negadas y vencidas por el poder de las primeras.

Para entender la conceptualización de Trousson vale revisar las características de las utopías que da: insularismo, desprecio del comercio, regularidad, uniformidad social, igualdad y supresión de las clases sociales, dirigismo escrito, colectivismo, énfasis en la educación, visión a la vez totalitaria y humanista. Es evidente que esta literatura utópica nace de la realidad europea y no corresponde con la historia latinoamericana: su carácter de "Nuevo Mundo" ante la conquista española y su consecuente visión como "campo de experimentación", su diversidad, heterogeneidad y la convivencia de los distintos, sus choques culturales y sus procesos de dominación-liberación. 
Es por eso que en América Latina la utopía superó la idea de sitio, de espacio concreto, de modelo organizativo predeterminado, regulador e incluso autoritario. Por eso nos apoyaremos en otras visiones menos apegadas a esa idea de modelo, o de género, sino que rescatan la utopía como actitud del pensamiento y como espíritu que se refleja en él. Es decir, la utopía no es la obra literaria sino que está presente en ella, la recorre.

Dubois declara que la utopía "es un género con reglas fijas y muy estrictas", pero reconoce que "el espíritu utópico puede perfectamente insinuarse en las producciones novelescas, los ensayos políticos o morales, los tratados jurídicos o las relaciones de viajes reales o imaginarios" (en Trousson, p.23). Aunque dice que no se puede confundir el espíritu utópico con la utopía, en nuestro continente la producción de esas utopías de "reglas fijas" no es significativo, pero el espíritu utópico es innegable.

Por su parte, Suvin afirma que:

La utopía es la construcción verbal de una comunidad casi humana particular, en la que las instituciones sociopolíticas, las normas y las relaciones individuales están organizadas según un principio más perfecto que en la sociedad del autor y esa construcción opuesta se basa en la distanciación nacida de la hipótesis de una posibilidad histórica diferente (en Trousson p.27)

Aquí se sigue enmarcando la utopía en un género literario, pero la pone como lectura crítica de la sociedad, y construida sobre la creencia en una posibilidad histórica alternativa.
Para Latinoamérica, un concepto como el de Mannheim es interesante, pues llamaba "ideología" a las ideas políticas inspiradas o sostenidas por el sistema en el poder, y "utopía" a las que se oponían a él, que lo impugnaban (en Trousson, p.37). Pero la idea de que los europeos vieran como utopía la construcción de su Nuevo Mundo podría cuestionarlo, pues el poder tenía de alguna manera una visión utópica, sin ser este de oposición.

Esto nos dice que la utopía no necesariamente está relacionada con la posición en el poder, sino definida por la realidad concreta, histórica y social. No compartimos la visión de Lalande, que define utopía como "un ideal político social seductor, pero irrealizable, en el que no se tienen en cuenta los hechos reales, la naturaleza del hombre y las condiciones de vida" (en Trousson, p.63), pues le quita su potencial histórico y transformador.

En este sentido, queremos ir perfilando la utopía. Afirma Ricoeur que "un modelo que coloca la utopía en contraposición a la realidad es inadecuado, porque la realidad no es algo dado, sino que es un proceso" (Ricoeur, p.30). Así, se pregunta: “¿no podemos decir entonces que la imaginación misma -por obra de su función utópica- tiene un papel constitutivo, en cuanto a ayudarnos a repensar la naturaleza de nuestra vida social?" (Ricoeur, p.58). Esta posibilidad de que la utopía tenga a la vez carácter crítico y transformador tiene varios refuerzos.

Varios autores ven la utopía como una lectura crítica y radical de las condiciones en las cuales nace. Pero esa construcción 
nacida de la crítica, no necesariamente es un modelo irrealizable, sino un espíritu que deconstruye y reconstruye ese contexto, a partir de posibilidades. El mismo Trousson afirma:

Tomar la utopía por una quimera, un sueño gratuito, es pasar por alto que en muchos casos es una obra inspirada por las circunstancias. Así, la utopía es por esencia histórica, ya que está determinada por sus relaciones con la realidad (Trousson, p.41)

Podemos considerar la utopía como una combinación de la lectura crítica del entorno, y proyecciones alternativas. "Ernst Bloch reivindica la virtud de "soñar despierto" como el primer indicio de pensamiento utópico estructurado. A ese mero "soñar" debe seguir una voluntad de acción (aspecto volitivo) para marcar la verdadera intención utópica" (Ainsa, 1990, p.17). Aquí sin duda estamos acercando la utopía a otro campo: el de la subjetividad colectiva, la expectativa crítica y el mundo de las posibilidades, de la acción, de la construcción.

Hinkelammert afirma que "el contenido de lo posible es siempre algo imposible que da sentido y dirección a lo posible (...) Es decir, todo posible existe en referencia a una plenitud imposible, en relación con la cual es experimentado y argumentado el marco de lo posible" (Hinkelammert, 1995, p.27). Esta visión nos permite aventurar que el pensamiento utópico latinoamericano ha sido siempre una construcción colectiva, basada en necesidades sumamente concretas ante los procesos históricos vividos, y no la elaboración de modelos "perfectos" de organización social. En este sentido decía Vera:

(...) No se trata de crear una nueva utopía, ni mucho menos de intentar sostener viejas ilusiones, sino de afrontar los retos del destino histórico de este oscuro fin de siglo con los instrumentos de un pensamiento emancipador y de un proyecto ético al mismo tiempo consciente de sus raíces históricas y abierto a la emergencia de lo nuevo. (Vera, p.4)

Ahora, si planteamos que la utopía es un espíritu, y no un género literario, ¿cómo encontrarla en la literatura? Maturana enmarca la utopía como una construcción literaria, sin embargo, la diluye dentro de la creación no necesariamente utópica como género, uniéndola a un compromiso ético coherente con la realidad latinoamericana. Así, encontramos la utopía en

... obras literarias tales como novela, ensayos, poemas... que expresan añoranza por un modo de convivir humano en dimensiones de honradez, cooperación, justicia, equidad, respeto por el otro, integración armónica con el mundo natural, y en el que no exista la miseria ni se produzca el abuso sistemático como modo de vivir. Un modo de vivir humano sin discriminaciones sexuales, raciales, de inteligencia o de clase, y sin sometimiento a una autoridad que subordine sistemáticamente unos seres humanos a otros. (Maturana, p.1)

Ahora, y aquí una distancia con su enfoque, desde la perspectiva de la relación 
entre utopía y literatura: al definir aún que la utopía es la obra literaria determinada que contiene ese ideario, se comete el error que cuestionamos.

Nos preguntamos por qué la utopía no es precisamente la construcción colectiva de ese ideario, independientemente de su concreción en un texto, sino más bien a partir de su existencia en el imaginario colectivo. Es decir, la obra es el marco formal de la utopía, pero no la utopía en sí. Ese sigue siendo el modelo de Moro que la realidad latinoamericana supera, al construir sus mundos ideales constantemente en otros procesos históricos, de formas diferentes.

Aun antes de plasmarse en una obra utópi$c a$, existe un espiritu: historicidad, lecturas críticas de la realidad, sueños, esperanzas, proyectos, expectativas, propuestas, deseos, luchas, resistencias. Si ese conjunto es el contenido de la utopía, por tanto, es en sí mismo la utopía. Dubois hablaba de no confundir el espiritu utópico con la utopía. Si queremos ser consecuentes en no querer mezclar el modelo de la Utopía de Moro con estas formas de utopía que se han planteado, es correcta la separación. Sin embargo, si tomamos la producción literaria latinoamericana, notamos que la creación de pensamiento utópico ha sido permeada por situaciones históricas particulares, que hacen que no se produzcan descripciones de sociedades ideales utópicas en el estilo europeo. Pero sí se puede delinear lo que consideremos utopía en formas propias de nuestra creación literaria, pensamiento político, arte o filosofía.
Por lo tanto, es importante sacar la utopía de su marco formal, para que cuando la busquemos reflejada en la literatura rescatemos que su construcción es colectiva, no individual, y que la obra literaria es solo un canal. Afirma Octavio Paz que "una literatura nace siempre frente a una realidad histórica y, a menudo, contra esa realidad (...) (en Durán, p.6). Entonces entendemos que en ella podamos hallar con facilidad la utopía, que se nutra de esta y que la construya sin necesidad de coincidir en un marco reglamentado.

Tratando de unir estas consideraciones, entendemos que no hay un marco cerrado de utopía, y que esta puede asumirse ampliamente como los sueños, añoranzas y proyecciones creativas que se construyen en el imaginario colectivo de un pueblo como horizonte posible y deseable, y que toman unidad a partir de la lectura crítica y ética de su contexto histórico y de la esperanza en su transformación. Siendo así que la utopía está en el imaginario social, ésta puede ser reflejada por las creaciones culturales de esa sociedad, por su arte y literatura, su ideología, su discurso y acción política; y tiene ejes constantes que surgen de su contexto particular, pero es dinámica en cuanto a la diversidad que la forja y a sus cambios de cara al movimiento de la Historia. 


\section{Bibliografía}

Ainsa, Fernando. Necesidad de la Utopía. Montevideo: TUPAC-ediciones y editorial NORDAN, 1990.

Durán Luzio, Juan. Creación y utopía, letras de Hispanoamérica. Heredia: Editorial de la Universidad Nacional, 1979.

Goldman, Lucien. Epistemología de la sociología lógica y conocimiento científico. París: Gallirmard, 1986.

Hinkelammert, Franz J. Cultura de la esperanza y sociedad sin exclusión. San José: DEI, 1995.
Maturana, Humberto. Utopía y ciencia ficción, URL: www.lxxl.pt/babel/ biblioteca/maturana.atml

Ricoeur, Paul. Ideología y utopía. Bacelona: Gedisa, 1999.

Servier, Jean. Historia de la Utopía. Caracas: Monte Ávila Editores, 1969.

Trousson, Raymond. Historia de la literatura utópica. Barcelona, Península, 1995.

Vera, Juan Manuel. Utopía y pensamiento disutópico. En: Iniciativa Socialista, URL: www.inisoc.org/utopía.htm 